\title{
GESTÃO DE PESSOAS: ANALISANDO AS POLÍTICAS E PRÁTICAS APLICADAS EM UM CENTRO ESPÍRITA
}

\author{
Vinícius Porto de Avila ${ }^{1}$ \\ Camila Vieira Müller ${ }^{2}$ \\ Angela Beatriz Busato Scheffer ${ }^{3}$
}

\begin{abstract}
RESUMO: Este artigo analisa as políticas e práticas de gestão de pessoas realizadas em um centro espírita. Inicia abordando alguns aspectos sobre políticas e práticas de gestão de pessoas. A seguir, aborda os temas religião e espiritualidade com o objetivo de contextualizar o espiritismo. Logo em seguida, apresenta o centro espírita pesquisado e os procedimentos metodológicos utilizados no estudo. Prosseguindo, são descritas e analisadas as políticas e práticas de gestão de pessoas adotadas pela organização espírita. Concluindo, busca-se responder se as políticas e práticas de gestão de pessoas, segundo a percepção de diferentes atores organizacionais, sofrem influência da espiritualidade.
\end{abstract}

Palavras-chave: Gestão de pessoas. Políticas e práticas. Espiritismo.

\section{PEOPLE MANAGEMENT: ANALYZING THE POLICIES AND PRACTICES APPLIED IN A SPIRITIST CENTER}

ABSTRACT: This article analyzes the policies and practice of people management carried out in a spiritist center. It begins by addressing some aspects of people management policies and practices. Next, it approaches the themes religion and spirituality with the purpose of contextualizing the spiritism. Soon after, it presentes the spiritist center researched and the methodological procedures used in the study. Following, the policies and practice of people management adopted by the organization are described and analyzed. In conclusion, we seek to answer if the

\footnotetext{
${ }^{1}$ Doutorado em Administração, em andamento, pela Universidade Federal do Rio Grande do Sul (UFRGS). Graduando em Filosofia pela Universidade Federal de Pelotas (UFPEL). Mestre em Administração pela Universidade Federal do Rio Grande do Sul com bolsa CNPq . Bacharel em Administração de Empresas pelas Faculdades Riograndenses. Osório. Rio Grande do Sul. Brasil. Email: adm.viniciusavila@gmail.com

${ }^{2}$ Possui graduação em Administração pela Escola Superior de Propaganda e Marketing (2014). Atualmente cursa MBA em Gestão Empresarial na FADERGS. Universidade Federal do Rio Grande do Sul. Porto Alegre. Brasil. E-mail: mullervcamila@hotmail.com

${ }^{3}$ Doutorado em Administração pela Universidade Federal do Rio Grande do Sul, Brasil (2003).

Professor associado da Universidade Federal do Rio Grande do Sul. Porto Alegre. Brasil. E-mail: abbscheffer@ea.ufrgs.br
}

Ágora: R. Divulg. Cient., v. 22, n. 1, p. 64-86, jan./jul. 2017 (ISSNe 2237-9010) 
policies and practices of people management, according to the perception of different organizational actors, are influenced by spirituality.

Key-words: People management. Policies and practices. Spiritism.

\section{INTRODUÇÃO}

Os modelos administrativos vigentes têm focado em posturas mais participativas, enfatizando investimentos afetivos, emocionais e até mesmo espirituais no ambiente laboral. Esses modelos buscam integrar à gestão de pessoas uma noção subjetiva da realidade humana aliada ao seu contexto histórico e social (SILVA; SIQUEIRA, 2009). Se no passado a espiritualidade estava mais restrita a religiões, igrejas, mosteiros e diversas outras congregações religiosas, hoje ela penetra em campos inesperados, especialmente no ambiente de trabalho. Insere-se numa dimensão estratégica, proporcionando significado à missão da organização e ao trabalho das pessoas. A espiritualidade no trabalho, então, seria uma nova perspectiva de humanização do trabalho. Dessa forma, "gestão e espiritualidade", embora a primeiro momento pareçam assuntos desassociados e distintos são, do contrário, complementares (MENEGAT, 2014; SILVA; SIQUEIRA, 2008).

Reconhecendo a relevância dos estudos envolvendo espiritualidade na gestão, o presente trabalho procura analisar a influência da espiritualidade nas práticas de gestão de pessoas da Sociedade Beneficente Espírita Bezerra de Menezes (SBEBM). Torchi (2013) define "Centro Espírita" como um núcleo de estudos, de fraternidade, de oração e de trabalho (TORCHI, 2013, p. 228-229). Na condição de "Casa Espírita", a SBEBM tem como objetivo primordial o auxílio no progresso moral e intelectual dos indivíduos, bem como despertar a consciência de seus deveres e responsabilidade perante o próximo e perante a si mesmo. É uma verdadeira escola, porém, destituída do sentido institucional, cujo objetivo é divulgar a Doutrina Espírita à luz dos ensinamentos de Cristo, com o compromisso social de educar a humanidade, fornecendo bases para o autoconhecimento e descobertas do verdadeiro sentido da vida (TORCHI, 2013; PIRES, 1979).

Um dos pesquisadores frequenta o SBEBM como estudante da Doutrina Espírita desde o ano de 2006, já tendo participado de diversas atividades nesse 
período, percebeu certas características peculiares da organização. Dentro dos dogmas do Espiritismo, é naturalmente aceito pelos adeptos que existem aspectos além da existência terrena que influenciam atividades cotidianas de qualquer natureza. Sendo assim, o local foi, então, considerado adequado para o objetivo geral do estudo: identificar e descrever as práticas e políticas de gestão de pessoas realizadas em um Centro Espírita, verificando a influência da espiritualidade nas mesmas. Para discorrer do desenvolvimento deste estudo apresentamos, a seguir, o referencial teórico e o método de pesquisa e, na continuidade, a análise dos achados em campo e as considerações finais.

\section{POLÍTICAS E PRÁTICAS DE GESTÃO DE PESSOAS}

Nas palavras de Davel e Vergara (2001, p.47), o termo gestão de pessoas compreende "uma construção social baseada em uma visão particularizada de organização e de pessoa, variando no tempo e no espaço". Assim, a forma como as pessoas são geridas/instruídas sofre influência das diretrizes impostas pela empresa, além de estar presente a questão pessoal dos gestores. Considerando-se que as pessoas que participam de uma organização são as responsáveis pela criação, inovação e vitalidade das ações, as políticas de gestão de pessoas acabam tendo uma importância singular para as empresas (HOMEM; OLTRAMARI; BESSI, 2009).

O papel das políticas e práticas de gestão de pessoas, tanto em relação aos atuais membros da organização, quanto à seleção e socialização de novos membros, é viabilizar a transmissão de soluções e a construção das bases dos compartilhamentos e das percepções sobre o que é certo ou errado para as organizações (SCHEIN, 1985). Em tais processos são considerados os conflitos, os dilemas e as ambiguidades, reconhecendo-se, também, as complexidades inerentes às subjetividades humanas (DAVEL; VERGARA, 2001). Destarte, a heterogeneidade do contexto organizacional é reconhecida como algo positivo, e não, simplesmente, um problema a ser resolvido. Considera-se, portanto, a importância das diferenças, cabendo o seu gerenciamento à administração, sem que se elimine-as (CHANLAT, 1999; DA SILVA; JUNQUILO, 2003). 
As práticas de gestão, por outro lado, referem-se a um conjunto de práticas administrativas as quais são executadas pela direção de uma empresa a fim de atingir os objetivos por ela fixados (CHANLAT, 1999). Compreende-se, dentro dessa definição, o estabelecimento de condições de trabalho, a organização do trabalho, a natureza das relações hierárquicas - bem como o tipo de estrutura organizacional, sistemas de avaliação e controle, enquadrando-se também as políticas para gestão de pessoas (HOMEM; OLTRAMARI; BESSI, 2009).

\subsection{RELIGIÃO E ESPIRITUALIDADE}

A fim de se firmar como conhecimento autônomo, tradicionalmente a ciência distancia-se de aspectos ligados à religião e a espiritualidade. Para Da Silva (2008), há uma imensa diversidade conceitual e multidisciplinar, o que, invariavelmente, resulta em confusões e torna imperativa a distinção dos conceitos de "espiritualidade e religião" a fim de compreender sua influência na gestão.

A "religião" pode ser também compreendida como um conjunto de crenças e práticas relativas a algo sagrado, vividas tanto individualmente quanto coletivamente, além de modelar convicções e padrões de comportamento. A espiritualidade, por sua vez, é algo referente às questões de natureza pessoal, fundamental para a busca individual de compreensão de respostas de questões fundamentais da vida, podendo, ou não, levarem ou estarem vinculadas a rituais religiosos. É transcendental, isto é, ligada a uma experiência fora do campo material/existencial do cotidiano, além de possuir caráter de conexidade - isto é, intimamente interligada com as pessoas, com a natureza e com o cosmos (DA SILVA, 2008; UNRUH; VERSNEL; KERR, 2002). São, portanto, termos essencialmente complementares, sendo a religião ligada ao sistema institucionalizado, enquanto a espiritualidade é relativa às experiências de caráter mais individual.

Para o presente trabalho, considera-se a complementaridade dos dois conceitos conforme foram apresentados, devido à natureza da Doutrina Espírita que permeia o objeto de estudo. O termo "espiritualismo" é um gênero dentro de todas as correntes religiosas. No momento em que se intenta identificar um segmento religioso específico, utiliza-se Catolicismo, Budismo, Espiritismo. Portanto, todo 
espírita é espiritualista, mas nem todo espiritualista é espírita. De maneira bem objetiva, pode-se dizer que a espiritualidade diz respeito à crença, enquanto o Espiritismo é a religião (TORCHI, 2013). É nesse sentido que se faz necessário esclarecer aspectos fundamentais do Espiritismo no item subsequente.

\subsection{ESPIRITISMO}

O Espiritismo teve sua origem na metade do século XIX, por conta de uma onda de interesse por fenômenos mediúnicos que se espalhou pela Europa e América do Norte. Esse movimento ficou conhecido como "Espiritualismo Moderno" (DOYLE, 1995). Como uma divisão do Espiritualismo Moderno, o Espiritismo teve sua origem na França quando Hippolyte Léon Denizard Rivail, sob o pseudônimo de Allan Kardec, realizou uma investigação científica sobre as supostas manifestações dos espíritos, comparando e organizando as respostas obtidas através de médiuns de diversos países. Assim, em 1857 essas informações resultaram num construto teórico único, que culminou na publicação do "O Livro dos Espíritos". A fim de buscar uma definição para essa filosofia, Allan Kardec cunhou o termo "Espiritismo" ou "Doutrina Espírita" (ALMEIDA, 2004; KARDEC, 2008).

No campo intelectual, o positivismo de August Comte encontrava grande repercussão, uma vez que considera o conhecimento científico baseado na observação de fatos e nas relações entre eles (HENRIQUE, 2000). É na lógica positivista que os preceitos Espíritas foram organizados no Livro dos Espíritos, bem como em todo o corpo teórico da Doutrina escrito por Allan Kardec.

Entre os princípios Espíritas básicos é possível destacar: a existência de Deus, imortalidade da alma, reencarnação, evolução, mediunidade e aceitação da ética cristã, enfatizando a prática da caridade (entendida de modo mais abrangente que a simples esmola). Para os espíritas o conceito de caridade pode ser compreendido através da seguinte frase de Kardec (2008, p. 275) "Benevolência para com todos, indulgência para com as imperfeições alheias, perdão das ofensas" (ALMEIDA, 2004).

No meio espírita difunde-se o caráter de "tríplice aspecto" do Espiritismo: é implicitamente (i) religião, no momento em que o conhecimento propiciado implica em questões-chave da moral, que coincide com os princípios propostos por Cristo; 
Explicitamente (ii) filosofia, visto que convida o homem a refletir criticamente a tudo o que se afirma ou faz, em todos os setores de sua existência; Por fim, é essencialmente uma (iii) ciência, calcada na observação positivista, que tem por objeto $O$ conhecimento das leis do princípio espiritual (CHIBENI, 2003; FERNANDES, 2008; ARRIBAS, 2008).

\subsection{SOCIEDADE BENEFICENTE ESPÍRITA BEZERRA DE MENEZES (SBEBM)}

A Sociedade Beneficente Espírita Bezerra de Menezes (SBEBM) foi fundada no dia 16 de abril de 1917 na cidade de Porto Alegre. A instituição tem os seguintes objetivos: (i) o estudo do Espiritismo sob seu tríplice aspecto de ciência, filosofia e religião à luz do Evangelho de Jesus, alicerçado na codificação de Allan Kardec; (ii) promover o ensino e a difusão da Doutrina Espírita, mantendo a fidelidade doutrinária (SOCIEDADE BENEFICENTE ESPÍRIRA BEZERRA DE MENEZES, 2005).

A sociedade já sofreu alguns preconceitos sociais. Na época da recémproclamada república, suas reuniões eram tidas como atividades de um grupo de pessoas excêntricas, da então, nova doutrina. Atualmente, não existe mais preconceito devido ao reconhecimento pelo trabalho prestado junto à comunidade. Espíritas, bem como membros de outras religiões e filosofias, recebem na sociedade Bezerra de Menezes uma resposta positiva através de amor, educação, saúde e solidariedade. Hoje, a sociedade conta com cerca de 3.000 voluntários, que realizam aproximadamente 750.000 atendimentos por ano (SOCIEDADE BENEFICENTE ESPÍRIRA BEZERRA DE MENEZES, 2016). A administração atual da SBEBM é composta pelos conselhos administrativo, deliberativo e fiscal, eleitos a cada dois anos entre os sócios da instituição. 
Figura 1 - Estrutura organizacional

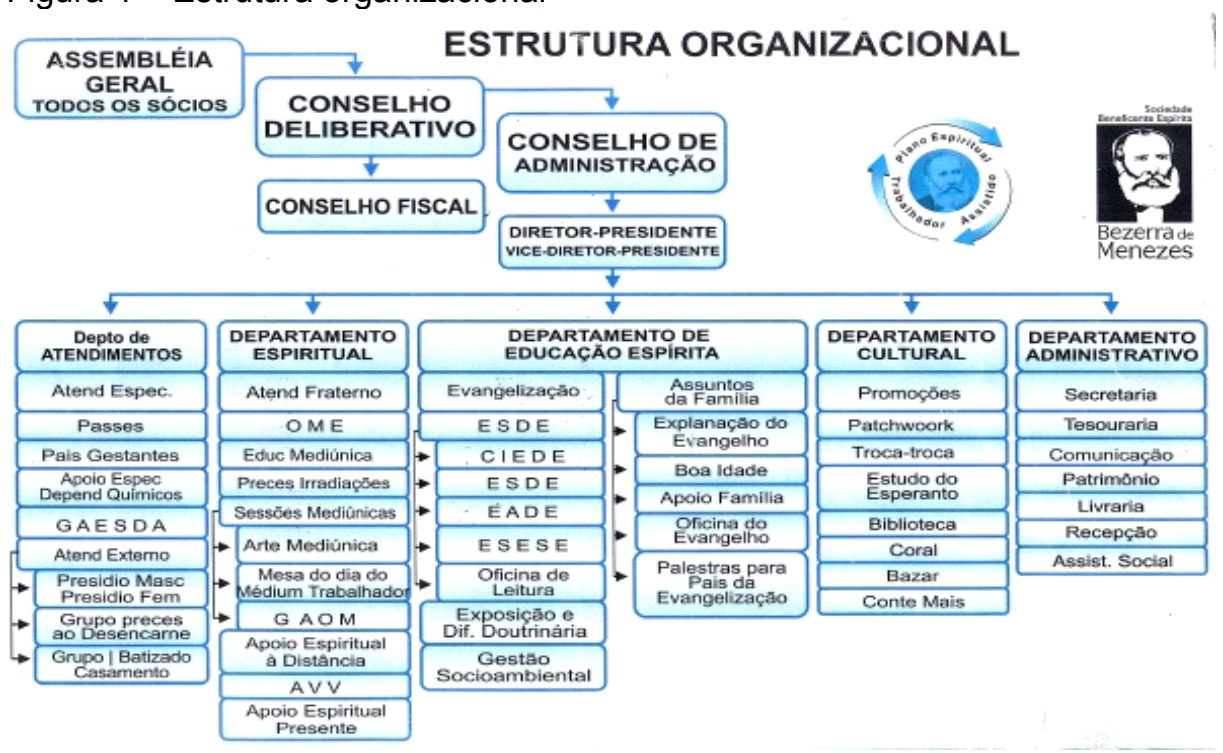

Fonte: SBEBM

\section{MÉTODO}

Optou-se pela realização de uma pesquisa exploratória de natureza qualitativa. A pesquisa qualitativa é capaz de introduzir a questão do significado e da intencionalidade como intrínsecos aos atos, às relações e às estruturas sociais (BARDIN, 2009). A fim de atingir os objetivos propostos utilizaram-se técnica etnográficas (CAVEDON, 2008; GODOY, 1995). Godoy (1995) afirma que a pesquisa etnográfica engloba a descrição dos eventos que ocorrem na vida de um determinado grupo de indivíduos, assim como a interpretação do significado destes eventos para a cultura desse grupo. Contudo, o estudo caracteriza-se como uma experiência etnográfica, e não como uma etnografia, uma vez que o tempo de imersão dos pesquisadores em campo não se alongou conforme desejado. A observação participante, as entrevistas semiestruturadas e a pesquisa documental foram as técnicas de coleta de dados aplicadas.

Caracterizando-se, assim, a realização da observação-participante. $\mathrm{Na}$ condução do presente estudo foram realizadas seis entrevistas. Todos os entrevistados eram colaboradores não remunerados (diretor-presidente, vice-diretor presidente, médium, facilitador ESDE e 2 voluntários do departamento administrativo). As entrevistas foram gravadas e, posteriormente, transcritas. Obtivemos acesso aos seguintes documentos: (1) estatuto social da SBEBM; (2) estrutura organizacional da SBEBM; (3) página de internet da SBEBM 
(www.sbebm.org.br); (4) projeto de gestão administrativa e recursos humanos (parte 1). As informações coletadas foram interpretadas utilizando o método de análise de conteúdo (BARDIN, 2009). Os achados foram agrupados em duas categorias: (1) materiais e; (2) espirituais. É importante ressaltar que as duas categorias entrecruzam-se em alguns momentos.

Realizou-se uma descrição densa (GEERTZ, 1989) dos dados coletados, já os aproximando ao referencial teórico. De modo a reduzir a probabilidade de interpretações errôneas ou equivocadas, recorreu-se à triangulação de técnicas de coleta de dados (observação participante, entrevistas semiestruturadas e pesquisa documental), o que permitiu que as informações obtidas fossem confrontadas, possibilitando o aprofundamento no tema.

A seguir serão descritos e analisados alguns aspectos da gestão e, especificamente, da gestão de pessoas da SBEBM.

\section{SBEBM: ORGANIZAÇÃO, GESTÃO, EDUCAÇÃO E ESPIRITUALIDADE}

A categoria material aborda as questões relacionadas à organização, a educação e a gestão do objeto de estudo. A SBEBM não é reconhecida por seus colaboradores como organização de cunho religioso, mas sim social e filantrópico, caracterizando-se assim como uma organização do terceiro setor:

\footnotetext{
A sociedade espírita, ela é uma sociedade filantrópica, humanista [...]. Ela não é uma sociedade [organização] religiosa, porque ela se inspira nos postulados filosóficos científicos e ético-moral do espiritismo [...] da Sociedade [SBEBM] como uma organização social, que tem um compromisso social.[...] e consequentemente que precisa ter um patrimônio econômico, [...] da colaboração fraterna e espontânea dos que assumem o compromisso de serem espíritas por filosofia de vida, e, consequentemente, a necessidade de colaborar para a manutenção [...] e um meio de arrecadar recursos para promover a filantropia e a ajuda humanitária (MÉDIUM, ENTREVISTA, JULHO/2016).
}

A questão de ajuda humanitária e filantrópica que permeia os objetivos da SBEBM como organização social estão em conformidade com os preceitos Espíritas. O professor José Herculano Pires, defensor da pureza dos princípios Kardecistas, publicou em seu "Curso Dinâmico de Espiritismo" (1979), ressalta o papel do Espiritismo como incentivador da transformação social, por meio de práticas que determinam a responsabilidade do Espírita na sociedade por meio da luta pelo 
aprimoramento moral dos indivíduos em conformidade com os ensinamentos de Cristo. Percebe-se, então, que embora o aspecto religioso não seja abertamente declarado, ele está implícito nas atividades da casa. Como resultado, a instituição proporciona ensinamentos que possibilitam a tomada de consciência no que diz respeito ao papel do indivíduo na sociedade, e seus compromissos como Cristãos. O discurso do Diretor-Presidente apresenta essa ideia:

Quem vem para o Centro Espírita vem para o autoconhecimento [...] é um local para o ser humano se autoconhecer. Que ele é um ser que não morre. Que seus atos, todos, atos incluindo os pensamentos e tem responsabilidade sobre isso. E ele começa a se dar conta que ele é um agente modificador da sociedade onde ele está inserido [...] (DIRETORPRESIDENTE, ENTREVISTA, JULHO/2016)

Ademais, evidencia-se que a espiritualidade entra em pauta novamente quando se diz respeito à estrutura organizacional da SBEBM. O médium entrevistado afirma que existem dois lados da instituição, o físico e o espiritual:

É uma empresa! Uma empresa espiritual. Possui o lado físico e o lado espiritual. É uma empresa do bem. [...] é uma Sociedade que obedece a regulamentação civil. A legislação. Então, é registrada em cartório, etc. Então, ela tem um conselho de administrativo, um conselho deliberativo, e a gestão, diz um aspecto administrativo material, e um aspecto espiritual. As coisas se complementam e, nessa visão holística e harmônica, sem competição de qualquer natureza. Tem um corpo social (MÉDIUM, ENTREVISTA, JULHO/2016).

A situação do centro espírita dentro do plano material pode ser fundamentada no seu caráter diante do Terceiro Setor - expressão utilizada a partir da década de 1990 a fim de designar sociedades civis organizadas, mantidas por doações, mantida por doações, que desenvolve voluntariamente atividades relativas à qualidade de vida. De acordo com o Diretor-Presidente entrevistado:

Como no terceiro setor é uma prestação de serviço, nós preparamos a sociedade, que é a função religiosa. Bom, então onde é que a casa busca seus recursos? [...] na doação dos próprios sócios (DIRETORPRESIDENTE, ENTREVISTA, JULHO/2016).

Assim, como uma organização do terceiro setor, buscam-se no voluntariado seus recursos financeiros e para manutenção de suas atividades. Na SEBBM existem trabalhadores remunerados e trabalhadores voluntários. Os remunerados 
ocupam alguns cargos administrativos, de segurança e de serviços gerais. As demais funções exercidas na casa são realizadas por trabalhadores voluntários. Não há restrição de público: qualquer pessoa pode frequentar o centro espírita. Contudo, aqueles que desejam trabalhar na instituição devem percorrer um caminho de estudos e orientação moral.

O departamento de educação espírita organiza a série de estudos sistematizados realizados no centro espírita. Inicialmente, ao entrar na instituição, o estudante e futuro candidato a voluntário realiza o CIEDE (Ciclo Introdutório de Ensino da Doutrina Espírita), o qual "refere-se a uma exposição dialogada voltada para os aspectos essenciais da Doutrina Espírita, tendo como objetivo preencher uma lacuna entre as palestras e o curso regular de Espiritismo, dando uma visão panorâmica e integradora da Doutrina" (SOCIEDADE BENEFICIENTE ESPÍRITA BEZERRA DE MENEZES, 2016). Existem dois pré-requisitos para a realização do CIEDE: ser sócio da casa e ter a idade mínima de dezoito anos.

O curso seguinte é denominado ESDE (Estudo Sistematizado da Doutrina Espírita), tem a duração de seis semestres com encontros semanais. O estudo caracteriza-se como sendo "teórico, racional e organizado da Doutrina Espírita, sem qualquer tipo de trabalho mediúnico, para aprofundar os conhecimentos da doutrina nos aspectos filosófico, científico e religioso" (SOCIEDADE BENEFICIENTE ESPIRITA BEZERRA DE MENEZES, 2016). Ter concluído o CIEDE e ter a idade mínima de dezoito anos são os pré-requisitos requeridos.

Os alunos que concluem o ESDE têm algumas opções, podem cursar o EADE (Estudo Aprofundado da Doutrina Espírita), o ESESE (Estudo Sistematizado do Evangelho Segundo o Espiritismo), ou tentar o ingresso no EEM (Estudo e Educação Mediúnica).

O EADE "visa ampliar os conhecimentos da Doutrina Espírita, procurando atender os interesses da turma nos mais diferentes assuntos e áreas do conhecimento dentro da visão espírita" (SOCIEDADE BENEFICIENTE ESPÍRITA BEZERRA DE MENEZES, 2016). O curso é dividido em EADE Científico, com duração de três semestres, e EADE Religioso, com duração de cinco semestres. A conclusão do ESDE é o único pré-requisito para ambos os cursos. O objetivo do ESESE é "ampliar os conhecimentos da obra da Allen Kardec" (SOCIEDADE BENEFICIENTE ESPÍRITA BEZERRA DE MENEZES, 2016). A duração do curso é 
de dois semestres. Assim como o EADE, o único pré-requisito é a conclusão do ESDE.

O Estudo e Educação Mediúnica (EEM) "tem por objetivo proporcionar conhecimento geral da mediunidade e favorecer o desenvolvimento natural das faculdades psíquicas dos participantes, por meio de dinâmicas pedagógicas específicas, úteis a prática mediúnica" (SOCIEDADE BENEFICIENTE ESPÍRITA BEZERRA DE MENEZES, 2016). Além disso, o curso de Educação Mediúnica faz parte do Departamento Espiritual, ao contrário dos outros cursos (CIEDE, ESDE, EADE e ESESE) que fazem parte do Departamento de Educação Espírita. Dele podem participar os estudantes egressos do ESDE. Tem a duração de seis anos, com encontros semanais, e conduzido por dois dirigentes/facilitadores em cada turma. Envolve estudo teórico e prático da mediunidade, fundamentado nas obras da Codificação. Ao término do curso, a preparação habilita os participantes ao exercício de todas as tarefas mediúnicas da Casa (SOCIEDADE BENEFICIENTE ESPÍRITA BEZERRA DE MENEZES, 2016).

Materialmente, a gestão da Sociedade é atribuída ao Departamento Administrativo, composto por 23 pessoas, entre funcionários remunerados, voluntários e membros da Administração (Diretor-Presidente e Vice-Diretor Presidente). Sobre o lado espiritual da Casa, a questão "administrativa", por assim dizer, é atribuída seu patrono, Bezerra de Menezes:

\footnotetext{
Espiritualmente, o patrono espiritual é Bezerra de Menezes, que foi um grande médium. Viveu. $\mathrm{E}$ ele tem, o que nós chamamos de uma egrégora espiritual, tem uma centena, milhares, de espíritos desencarnados, médicos e professores desencarnados, que trabalharam na casa, e que continuam, depois de mortos, desencarnados, fazendo parte dessa equipe, se tiver merecimento. (MÉDIUM, ENTREVISTA, JULHO/2016)
}

Para a compreensão da Doutrina Espírita, faz-se necessário admitir a existência de Deus, da alma, bem como a sua sobrevivência. Torchi (2013) esclarece os conceitos propostos por Kardec, definindo alma como "parte extracorpórea do ser humano, o ser pensante, além de um corpo material, é o Espírito encarnado" (TORCHI, 2013, p. 24). Nesse sentido, Kardec esclarece que Espírito nada mais é que a alma após o seu desligamento dos laços que a prendem ao corpo carnal, sendo o corpo apenas o seu envoltório, seu revestimento - isto é, com outras palavras, a alma após a "morte" (ou desencarne, para os Espíritas). 
Compreendido isso, na fala do Diretor-Presidente da Casa percebe-se que a gestão considera aspectos que transcendem o plano material e físico, dentro da crença Espírita. Tratam, então, o mundo como tridimensional, no qual eventos que vão além da racionalidade (de cunho espiritual) interferem no cotidiano e nas atividades da SBEBM:

[...] Duas dimensões é nosso plano, tá? Longitude e latitude. [...] quando se olha uma casa espírita se olha numa forma tridimensional. [...] nós chegamos também na terceira dimensão, até na própria matemática, existem coisas que acontecem conosco, assim, que não tá no nosso plano racional. [...] qual é a influência dos espíritos na administração da casa espírita? Quando se fala em plano espiritual... 90\% vem do plano espiritual. (DIRETOR-PRESIDENTE, ENTREVISTA, JULHO/2016)

Não obstante essa tridimensionalidade que permeia a Casa Espírita, a influência espiritual também se dá de diferentes formas. Todas as atividades no plano físico são orientadas pelo plano espiritual, que interfere de maneiras distintas entre os departamentos do SBEBM:

\begin{abstract}
A influência da espiritualidade na gestão vai se mostrar de maneira diferente, dependendo do setor ou dos setores em que cada um trabalha. $\mathrm{O}$ presidente vai ter uma visão, eu trabalho em dois ou três setores, então, nesses setores eu percebo uma influência muito grande dessa gestão que vem de cima, vem do mundo espiritual. [...]aí a primeira grande intervenção da administração espiritual, vamos dizer assim [...] são trazidos pela administração espiritual. (MÉDIUM, ENTREVISTA, JULHO/2016)
\end{abstract}

Com esses pontos abordados em vista, serão descritas e analisadas as práticas de gestão de pessoas realizadas no centro espírita objeto desse estudo. Buscar-se-á compreender se existe influência da espiritualidade nas ações realizadas com o objetivo de gerir as pessoas que trabalham na SBEBM.

\title{
5 AS PRÁTICAS E POLÍTICAS DE GESTÃO DE PESSOAS
}

A instituição não realiza processo de recrutamento, todas as vagas disponíveis na Casa são preenchidas pelos estudantes/voluntários assim que esses apresentarem as condições requeridas. Segundo um dos médiuns mais antigos da SEBBM, o centro não precisa recrutar pessoas para trabalhar: 
Nós não andamos de porta em porta seduzindo as pessoas para serem espíritas. Vem para o espiritismo a pessoa que já despertou a consciência, em busca de um significado para a sua existência. Ninguém bate lá, como os evangélicos fazem, e vai ler a Bíblia. $O$ espiritismo não precisa de propaganda... A vida leva a pessoa a se questionar. Qual a razão de ser da minha vida? Por que eu vivo? Morreu um parente, um familiar [...] e, apareceu um câncer... O sofrimento humano, nas suas múltiplas e infinitas modalidades de expressão, desperta a pessoa! Para buscar uma resposta. [...] É um trabalho de espontânea vontade (MÉDIUM, ENTREVISTA, JULHO/2016).

Os colaboradores da Sociedade, sejam eles remunerados ou não (menos de $10 \%$ dos colaboradores são remunerados), recorrem voluntariamente ao local com o intuito de ajudar e consequentemente serem auxiliados. Assim, os princípios básicos da Doutrina Espírita aparecem, novamente, transcendendo as práticas administrativas materiais da organização. Não há recrutamento propriamente dito, visto que parte do próprio indivíduo descobrir uma necessidade de auxílio e educação moral, com base nos ensinamentos de Cristo, para atender a essa busca por respostas existenciais. Um espírita convicto afirma "creio porque sei" em conformidade com os ensinamentos filosóficos e científicos da Doutrina (TORCHI, 2013, p. 132).

Em relação aos treinamentos realizados, conforme já citado, o centro espírita conta com um departamento de educação espírita. O crescimento dentro da hierarquia da Casa se dá com o desenvolvimento da mediunidade por meio do estudo da Doutrina. Os trechos transcritos apontam essa possibilidade:

\footnotetext{
Do ponto de vista espiritual, espiritismo como educação, nós temos vários cursos e os que aqui vem frequentar, e vem propor o espiritismo, eles têm um currículo, que leva de cinco a seis anos, então eles têm que fazer um curso de estudo sistematizado do espiritismo. [...] estudar as bases filosóficas, científicas e ético-moral do espiritismo. [...] é uma verdadeira faculdade! [...] isso [o estudo da doutrina] leva um cinco a seis anos, e, paralelamente, de acordo com as suas potencialidades mediúnicas, a nível mediúnico, para trabalhar e exercer a mediunidade (MÉDIUM, ENTREVISTA, JULHO/2016).
}

Voltando mais uma vez à analogia do Centro Espírita como uma empresa convencional, considerando a possibilidade de treinamento para a função de médium, no decorrer dos estudos dentro da SBEBM, também ocorre o desenvolvimento e aperfeiçoamento do indivíduo dentro da, digamos assim, "carreira mediúnica" no senso comum da expressão. O médium entrevistado explica esse processo:

Ágora: R. Divulg. Cient., v. 22, n. 1, p. 64-86, jan./jul. 2017 (ISSNe 2237-9010) 
A mediunidade é um atributo inerente ao gênero humano. Todo mundo tem. [...] você é um médium em potencial. [...] no teu processo de maturação... você passa a ter uma certa sensibilidade mediúnica, passa a ter uma certa percepção extra-sensorial. [...] E aí a gente vai te dar uma orientação espiritual-mediúnica para ver que tipo de problema você tá vivenciando [...] Então você passa a estudar e a frequentar um grupo de médiuns, que já estão com a mediunidade aflorada mas não tem nenhuma base espírita. (MÉDIUM, ENTREVISTA, JULHO/2016)

O estudo da Doutrina Espírita permite canalizar essa potencialidade, praticando o bem dentro da moral cristã, a fim de buscar o autoconhecimento e despertar níveis novos de consciência (TORCHI, 2013). A partir das falas dos entrevistados, percebe-se essa dificuldade:

\begin{abstract}
Não é como que vai ao cinema, 'bom, vou ver'. Não. Porque se você fez um curso teórico, ou teórico-prático, mas ainda você não tem as condições de enfrentar um trabalho mediúnico porque ele é muito complexo [...] você precisa canalizar essa mediunidade. Você vai esperar 6 anos [o tempo do estudo ou 'treinamento' dentro da SBEBM [...] (MÉDIUM, ENTREVISTA, JULHO/2016).
\end{abstract}

Dentro da Casa, para poder exercer as funções mediúnicas, é preciso concluir o nível do ESDE e participar de uma entrevista para verificar a possibilidade de ingresso na Escola Mediúnica. Esse processo faz parte do treinamento de médiuns na SBEBM, e embora tenha suas raízes nos processos formais de qualquer empresa convencional onde exista a possibilidade de ascender na carreira, dentro do Centro Espírita estudado ocorrem algumas particularidades. O lado espiritual se funde com o material, e a decisão final dos entrevistadores é fortemente inspirada pelos mentores espirituais da Casa. Caso o candidato à médium ainda não esteja preparado para assumir a função, os entrevistadores encarnados, com o auxílio da deliberação dos mentores espirituais, decidem se o candidato está apto, ou não, conforme explicam os entrevistados:

\footnotetext{
Evidente [que há influência espiritual]! [...] essa entrevista é feita pelo entrevistador. Que tem lá os critérios [...] há todo um processo que varia de pessoa pra pessoa. E se essa pessoa, digamos assim, deve frequentar a Escola de Médium, essa pessoa entra para a escola de Médium, o que é um imperativo espiritual, dela, e não depende da vontade de quem entrevista [...] não anula a capacidade de pensar e julgar do entrevistador. Mas ele tá sendo assistido, naquele momento da entrevista. Embora a gente não veja nada, nós temos uma assistência espiritual importante para poder ajudar (MÉDIUM, ENTREVISTA, JULHO/2016).
} 
Há também um cuidado no momento da seleção dos candidatos ao Estudo Mediúnico. Seguindo os princípios cientificistas do Espiritismo, mais de um entrevistado concede seu parecer, a fim de confirmar a interferência mediúnica durante o procedimento. Ao final do processo, caso as equipes espirituais e terrenas considerem que o candidato não está apto para as funções mediúnicas, mesmo após o estudo, são indicadas outras funções dentro das necessidades da SBEBM:

Para preservar a tua segurança, a tua saúde física, espiritual e psicológica, você continua frequentando a sociedade [...] Pode prestar alguma colaboração de ajuda na secretaria [...] Coisas que não te expõe a um intercâmbio mediúnico [...] não quer dizer que a pessoa fica jogada ao relento. (MÉDIUM, ENTREVISTA, JULHO/2016)

Já ocorreram (e ainda ocorrem) alguns desligamentos/demissões na SBEBM. O médium entrevistado explica como essas situações são tratadas dentro da Casa. Nesse processo de desligamento, é possível verificar que alguns pressupostos da Doutrina Espírita são implicitamente considerados, e servem como uma espécie de políticas e normas de conduta, uma vez que Doutrina Espírita assume que todos os Espíritos - tanto encarnados como desencarnados, estão submetidos à Lei Natural, a qual governa o Universo. Tal lei se divide em leis físicas e leis morais, e ambas são eternas e imutáveis, estando acima da legislação humana - consideradas transitórias e imperfeitas. Nesse sentido, a moral diz respeito à regra do bem proceder, ou a capacidade de distinguir o bem do mal. As leis físicas, por outro lado, dizem respeito às leis dos homens, aquelas que dominam a humanidade dentro de legislações específicas (TORCHI, 2013). Dentro SBEBM, então, as leis materiais - expressas no Estatuto, intercalam-se com as leis morais do Espiritismo, onde o rompimento de uma, necessariamente leva à ruptura da outra, conforme transcrição que segue:

\footnotetext{
Acontece só se a pessoa, ela for muito [...] desonesta, cometeu um ato [...] que fere toda a cosmoética, todo o preceito. Ela não é posta na rua, não é excluída. Ela é chamada, passa por um processo de análise, tá? E se oferece a opinião, a oportunidade pra ela se recuperar [...] E se não der, então ela é convidada a sair. Isso está no estatuto. Estatuto da casa. [...] O compromisso é a moral do Cristo. Amai o vosso próximo como a si mesmo, fazer o bem... pelo bem! Fazer o bem, não prejudicar, e ser útil à sociedade, à família, não roubar, não matar, não se corromper e não participar de corrupção (MÉDIUM, ENTREVISTA, JULHO/2016).
}

Ágora: R. Divulg. Cient., v. 22, n. 1, p. 64-86, jan./jul. 2017 (ISSNe 2237-9010) 
Para os Espíritas, as Leis Morais estão na consciência de cada indivíduo, e contém as regras da vida corpórea - isto é, as regras e normas de conduta conforme determinada população reconhece, bem como as que dizem respeito à relação do homem em um aspecto mais transcendental e Divino. E estejam expressas certas normas no estatuto, no SBEBM também não há uma fiscalização quanto ao seu cumprimento, partindo-se do pressuposto de que um Espírita deve ter consciência das suas obrigações morais - a qual é adquirida com estudo da Doutrina:

[...] Cada um é, digamos assim, o seu próprio juiz. [...] Ele é livre para fazer o que ele quiser, e é automaticamente responsável por tudo que ele faz de bom, de ruim ou de errado [...] E há toda uma fundamentação filosófica e ético-moral que embasa essa posição [...] essa postura filosófica e ética. (MÉDIUM, ENTREVISTA, JULHO/2016)

Assim, aspectos espirituais mais uma vez perpassam as práticas e políticas do Centro Espírita. No que diz respeito às políticas de Gestão de Pessoas, seu descumprimento tem um duplo aspecto (material/espiritual), e pode levar ao desligamento/demissão do colaborador. Ademais, por se tratar de uma organização do terceiro setor, existe também a possibilidade dos voluntários, por um motivo ou outro, deixarem o trabalho na Casa - o que já é encarado com naturalidade pela gestão da Casa.

\section{INFLUÊNCIAS ESPÍRITAS NA GESTÃO DE PESSOAS?}

As práticas e políticas de gestão de pessoas realizadas/desenvolvidas na SBEBM sofrem influências do plano espiritual? Os espíritos (ou até mesmo o próprio Patrono Bezerra de Menezes), através dos médiuns que trabalham na Sociedade, "têm voz" na forma como as pessoas são "gerenciadas" na instituição? Algumas situações relatadas nas entrevistas e presenciadas através da observação participante justificam tais questionamentos.

Quando um estudante conclui o ESDE, esse tem três opções para dar prosseguimento aos estudos da Doutrina: EADE, ESESE ou EEM. Caso queira cursar o EADE ou o ESESE, basta realizar a matrícula na Instituição. Contudo, no caso da Escola Mediúnica (EEM), a situação é diferente. Além da conclusão do 
ESDE, o estudante/trabalhador preenche um formulário e realiza uma entrevista de admissão:

\begin{abstract}
Acontece o seguinte [...] essa entrevista, ela é feita pelo entrevistador. Que tem lá os critérios, e ela pode, e deve pegar o seu nome, tirar uma nova orientação mediúnica para ver a situação da pessoa. Se deve continuar, ou fazer um sério tratamento espiritual. Ha todo um processo que varia de pessoa pra pessoa. E se essa pessoa, digamos assim, deve frequentar a escola de médium, essa pessoa entra para a escola de médium, o que é um imperativo espiritual, dela, e não depende da vontade de quem entrevista (MÉDIUM, ENTREVISTA, JULHO/2016).
\end{abstract}

Então, conclui-se que o plano espiritual tem influência nas decisões "materiais" que acontecem no centro espírita? Nas palavras do médium entrevistado, não há dúvidas:

Evidente! Tá? Não anula a capacidade de pensar e julgar do entrevistador. Mas ele tá sendo assistido, naquele momento da entrevista, embora a gente não veja nada, nós temos uma assistência espiritual importante para poder ajudar, nós que estamos orientando, a indicar a pessoa para o caminho certo (MÉDIUM, ENTREVISTA, JULHO/2016).

Inclusive, o médium ressalta posteriormente que a espiritualidade permeia toda e qualquer prática cotidiana. Em tal acepção, o espaço físico também é considerado um fator importante em relação à influência espiritual que ocorre nas diversas atividades de gestão desenvolvidas no centro espírita:

\footnotetext{
A influência mediúnica, ela independe de espaço, de tempo e do lugar. $\mathrm{Na}$ rua você tá recebendo influência de tudo quanto é tipo. No cinema, numa festa, no bordel, na boate, na empresa. Em qualquer lugar nós estamos num oceano de interferência positiva e negativa. [...] Em qualquer lugar... Em uma empresa há algo semelhante (MÉDIUM, ENTREVISTA, JULHO/2016).
}

Sob a ótica da espiritualidade influenciando toda atividade organizacional (e qualquer outra atividade humana), percebeu-se na fala dos entrevistados uma constante menção à "intuição". A intuição, para os Espíritas, é vista como uma manifestação da mediunidade de efeitos intelectuais, caracterizada por meio de pensamentos, vontades e ideias (TORCHI, 2013). É, portanto, referente a aspectos transcendentais do ser humano, não explicados racionalmente. De acordo com as transcrições dos entrevistados: 
A intuição é um tipo de mediunidade. A intuição é um nível, de elevada mediunidade. Tá? Então, todas as pessoas que estão fazendo esse trabalho já passaram por tudo isso. Elas também percebem, umas mais e outras menos, mas para evitar erros, a gente não age sozinho. A gente observa a entrevista, e submete, dá uma opinião, um parecer, e aquela pessoa vai ser analisada, e se tira uma nova orientação espiritual para se ver qual é o encaminhamento que deve ser dado a ela (MÉDIUM, ENTREVISTA, JULHO/2016).

No que diz respeito aos fatores transcendentais da natureza humana, alguns teóricos organizacionais (BARNARD, 1971; SIMON, 1971) já apontavam a existências de aspectos além da racionalidade que influenciavam a decisão do executivo nas organizações. Simon (1971), em concordância com Barnard (1971), articula em torno dos limites da racionalidade nos processos decisórios. Afirmam que boa parte das decisões dentro de uma organização são influenciadas por fatores psicossociais e culturais, e, portanto, fogem do controle administrativo-racional.

Os Espíritas, por outro lado, encaram esses fatores irracionais são resultado da influência da Espiritualidade, manifestando-se por meio da intuição:

[...] a espiritualidade transcende a racionalidade. Grandes decisões são tomadas por intuição(grifo nosso). Que ela está além da capacidade de raciocínio. Essa é a faculdade do Espírito. Ele ultrapassa aquele limite da racionalidade, da visualização, e atua na outra área espiritual (DIRETORPRESIDENTE, ENTREVISTA, JULHO/2016).

Dessa maneira, da mesma forma com a qual os teóricos organizacionais atribuem a fatores psicossociais certos aspectos que não são racionalmente explicados, sob o viés do Espiritismo muito pode ser atribuído à espiritualidade. Os entrevistados acreditam que os homens sofrem constantes influências energéticas, mediúnicas, que perpassam suas atividades cotidianas e interferem das mais diversas formas. No centro espírita analisado, tal influência se mostra mais evidente por ser um local onde se aceita a espiritualidade como algo inerente às atividades laborais. A Gestão de Pessoas, por outro lado, sofre mais profundamente essa influência, visto que diversos processos decisórios são calcados com base na intuição e outras atribuições ditas mediúnicas, que consideram aspectos transcendentais ao ser humano. 


\section{CONSIDERAÇÕES FINAIS}

A espiritualidade influencia as práticas e políticas de gestão realizadas no centro espirita estudado. A partir da análise das informações coletadas na observação participante, nas entrevistas e na análise dos documentos, a presente pesquisa revelou aspectos importantes das práticas de gestão de pessoas utilizadas pela SEBBM. Não obstante a espiritualidade assuma diversos conceitos, invariavelmente quando abordada diz respeito a aspectos que vão além da racionalidade humana. Dentro do viés do Espiritismo, assume um caráter peculiar, ancorada nas premissas da existência de Deus, do Espírito como uma extensão do ser (além da matéria), bem como em diversos preceitos próprios da Doutrina Espírita.

O caráter tríplice no qual foi construído (ciência, filosofia e religião), torna o Espiritismo um interessante suporte de análise no que tange à espiritualidade nas organizações, visto que dentro de seus ensinamentos reconhece constantemente a influência da espiritualidade não apenas dentro de uma Casa Espírita, mas permeando também atividades em todas as esferas do cotidiano. Dentro da SBEBM, contudo, tal influência perpassa, abertamente, as diversas atividades laborais da Casa. Confia-se na gestão espiritual como base para as decisões da gestão material, e ambas relacionam-se mutuamente - sendo tal fato visto com naturalidade dentro da organização.

Dada à complexidade do tema, o presente estudo é, acima de tudo, um convite a novas pesquisas com o intuito de perpassar o Espiritismo às diversas vertentes do conhecimento. Por ter sido verificado em cima de métodos positivistas, é ainda a única religião que a ciência não foi capaz de refutar (TORCHI, 2013). Sugere-se a realização de novas pesquisas, abordando outros/diferentes aspectos referentes à gestão de pessoas de uma instituição espírita.

\section{REFERÊNCIAS}

ALMEIDA, A. M. Fenomenologia das experiências mediúnicas, perfil e psicopatologia de médiuns espíritas. 2004. Tese (Doutorado). Universidade de São Paulo, 2004. 
ANDRIOTTI, F. K.; FREITAS, H. M.; MARTENS, C. D. P. Intuição na Decisão Instantânea. In: CONTECSI - International Conference on Information Systems and Technology Management. p. 2027-2056, 2012.

ARRIBAS, Celia da Graça. Afinal, espiritismo é religião? 2008. Tese (Doutorado). Universidade de São Paulo, 2008.

ARRUDA, V.C. M. A inteligência espiritual: espiritualidade nas organizações. São Paulo: Ibrasa, 2005.

ASHMOS, D. P.; DENNIS, D.Spiritualityatwork: A conceptualization and measure. Journal of management inquiry, v. 9, p. 134, 2000.

BARDIN, L. Análise de conteúdo. Lisboa, Portugal; Edições 70, LDA, 2009.

BARNARD, C.I. As funções do executivo. Cap.2, 6 e 7. São Paulo, Atlas, 1971.

BOFF, Leonardo. Espiritualidade: um caminho de transformação. Rio de Janeiro: Sextante, 2001.

BREWSTER, C. Comparing HRM policies and practices across geographical borders. In: STAHL, G.; BJORKMAN, I., Handbook of Research in International Human Resource Management. Cheltenham, UK: Edward Elgar Publishing, 2006.

CASALDÁLIGA, P.; MARIA VIGIL, J. Espiritualidade da libertação. Petrópolis: Vozes, 1996.

CAVEDON, N. Antropologia para administradores. 3. ed. Porto Alegre: Editora da UFRGS, v. 1. 182 p., 2008.

CENSO DEMOGRÁFICO 2010. Características da população e dos domicílios: resultados do universo. Rio de Janeiro: IBGE, 2011.

CHANLAT, J. F. Ciências sociais e management. São Paulo: Atlas, 1999.

CHANLAT, J. F. Modos de gestão, saúde e segurança no trabalho. In: DAVEL, E.; VASCONCELOS, J. M. (Orgs.). Recursos humanos e subjetividade. Petrópolis: Vozes, 2000.

CHIBENI, S. S. O espiritismo e seu tríplice aspecto: científico, filosófico e religioso. Reformador, ago. 2003.

ARRIBAS, Célia. O caráter religioso do espiritismo. Fragmentos de cultura, v. 23, n. 1, p. 3-16, 2013.

DA SILVA, R. R. Espiritualidade e Religião no Trabalho: possíveis implicações para o contexto organizacional. Psicologia Ciência e Profissão, v. 28, n. 4, p. 768-779, 2008

DA SILVA, R. R. Espiritualidade, religião e trabalho no contexto organizacional.

Psicologia em Estudo, v.14, n.3, p. 557-564, jul./set, 2009. 
DA SILVA, Alfredo R. L.; JUNQUILHO, Gelson S. Políticas de "RH", instrumentalização do consenso ou impulso à ambiguidade? Os dilemas do mundo real do trabalho na tentativa de "gerenciar" pessoas. In: ENCONTRO ANUAL DA ASSOCIAÇÃO NACIONAL DOS PROGRAMAS DE PÓS-GRADUAÇÃO EM ADMINISTRAÇÃO, 2003, Atibaia. Anais... Atibaia: ANPAD, 2003.

DENIS, L. No Invisível. 26.ed. Brasília: FEB, 2014.

DEVANNA, M. A.; FOMBRUN, C. J.; TICHY, N. M. Strategic human resource management. New York: John Wileyand Sons, 1984.

DAVEL, E.; VERGARA, S.C. Gestão com pessoas, subjetividade e objetividade nas organizações. In: DAVEL, E.; VERGARA, S.C. Gestão com pessoas e subjetividade. São Paulo: Atlas, 2001. p. 31-56,

FERNANDES, P.C. As origens do espiritismo no Brasil: razão, cultura e resistência no início de uma experiência (1850-1914). 2008. Tese (Doutorado). Universidade de Brasília, 2008.

GEERTZ, C. Uma descrição densa: por uma teoria interpretativa da cultura. In: A Interpretação das Culturas. Rio de Janeiro: Guanabara Koogan, 1989. p. 13-41,

GODOY, A. S. Pesquisa qualitativa: tipos fundamentais. Revista de Administração de Empresas. São Paulo, v. 35, n.3, p.20-29, 1995.

HENRIQUE, A. A revolução do espírito: perspectivas da ciência espírita. Natal, Brasil, 2000.

HILL, P. C.; PARGAMENT, K. Advances in the conceptualization and measurement of religion and spirituality. American Psychologist. v. 58, n. 1, p. 64-74, 2003.

HOMEM, I. D.; OLTRAMARI, A. P.; BESSI, V. G. A gestão de pessoas e seus mecanismos de sedução em um processo de aquisição. Revista de Administração Contemporânea, Curitiba, v. 13, n. 2, p.210-227, abr./jun., 2009.

KARDEC, A. Revista Espírita. Jornal de Estudos Psicológicos, 1863.

KARDEC, A. O Céu e o Inferno. Rio de Janeiro: FEB Editora, 2009.

KARDEC, A. Obras Póstumas. São Paulo: Instituto de Difusão Espírita, 1993.

KARDEC, A. O que é o espiritismo. 67.ed.Araras, São Paulo: IDE, 2006 (1859).

KARDEC, A. O Livro dos Espíritos. 177.ed. Araras, São Paulo: IDE, 2008 (1857).

KARDEC, A. O Livro dos Médiuns. 85.ed. Araras São Paulo: IDE, 2008 (1861).

KING J. E.; CROWTHER, M. R. The measurement of religiosity and spirituality. Examples and issues from psychology. Journal of Organizational Change Management, v. 17, n. 1, p. 83-101, 2004. 
KLEIN, G. Fontes do Poder: o modo como as pessoas tomam decisões. Lisboa: Inst. Piaget, 1998.

LACOMBE, B.; CHU, R.A. Políticas e práticas de gestão de pessoas: as abordagens estratégica e institucional. Revista de Administração de Empresas, v. 48, n.1, Jan. Imar, 2008.

LEHRER, J. Howwe decide. New York: HMH, 2009.

MAIOR, M.S. Kardec: a biografia. Rio de Janeiro: Record, 2013.

MENEGAT, J. Gestão e espiritualidade no ambiente de trabalho. Revista Iberoamericana de Ciencias Empresariales y Economía, v. 1, n. 1, 2014.

MOTTA, F. C. P. Teoria das organizações: evolução e crítica. Pioneira Thomson Learning, 2001.

PIRES, J. H. Curso dinâmico de espiritismo: o grande desconhecido. São Paulo: Editora O Clarim, 1979.

RIBEIRO, A.L. Gestão de pessoas. São Paulo: Saraiva, 2005.

SIMON, H.A. Comportamento administrativo. São Paulo: Editora da FGV, 1971.

SCHEIN, E. Organization culture sand leader ship: a dynamic view. San Francisco: Jossey-Bass, 1985.

SCHWARTZ, S. H.; HUISMANS, S. Value priorities and religiosity in our western religions. Social Psychology Quartely, v. 58, n. 2, p. 88-107, 1995.

SINGH, G.; CHOW, C.; WU, A. A critical analysis of the dominant strategic human resource management perspective. Artigo apresentado no encontro da Academyof Management, Honolulu, HI: AOM, 2005.

SIQUEIRA, D. Religião, religiosidade e contexto do trabalho. Sociedade e estado, Brasília, v. 20, n. 3, p. 717-724, set. /dez. 2005.

SOBRAL, F.; PECl, A. Administração: teoria e prática no contexto brasileiro. 2. ed. São Paulo: Pearson Education do Brasil, 2013.

SOCIEDADE BENEFICIENTE ESPÍRITA BEZERRA DE MENEZES. Estatuto Social. Porto Alegre, 2005.

SOCIEDADE BENEFICIENTE ESPIRITA BEZERRA DE MENEZES. Disponível em: $<$ http://www.sbebm.org.br/category/>. Acesso em: 30 de jul. 2016.

TORCHI, C. Espiritismo Passo a Passo com Kardec. Brasília: FEB, 2013.

UNRUH, A. M.; VERSNEL, J.; KERR, N. Spirituality un plugged: A review of comm analities and contentions, and a resolution. Canadian Journal of Occupational Therapy, v. 69, n. 1, p. 5-19, 2002. 
WALTON, R. E. Toward a strategy of eliciting employee commitment based on policies of mutuality. In: WALTON, R. E.; LAWRENCE, P. R. (Org.). Human resource management, trends and challenges. Boston: Harvard Business School Press, 1985. p. 35-65.

WRIGTH, P.; MCMAHAN, G. Theoretical perspectives for strategic human resource management. Journal of Management, v. 18, n. 2, p. 295-311, 1992.

VERGARA, S. C.; BRANCO, P. D. Organização humanizada: a organização necessária e possível. Revista de Administração de Organizações, São Paulo, v. 41, n. 2, p. 20-30, 2001.

Artigo recebido em: 12/03/2017

Artigo aprovado em: 11/08/2017 